\title{
Melhoramento humano biotecnocientífico: a escolha hermenêutica é uma maneira adequada de regulá-lo?
}

\author{
Biotechnoscientific human enhancement: \\ the hermeneutics choice is a good way to regulate it?
}

*Murilo Mariano Vilaça
** Maria Clara Dias

Resumo: Uma forma de compreender o humano é pela sua biologia, a qual pode ser vista como ambígua. Por um lado, há características biológicas correlacionadas a capacidades extremamente especializadas e complexas, as quais abrem possibilidades que lhe são particulares, distinguindo-o 'positivamente' dos outros seres vivos. Por outro, como todo ser vivo, há características que tornam a vida humana finita e relativamente vulnerável, as quais costumam ser 'negativamente' interpretadas. Em ambos os casos, há características biológicas que, em si, não são boas nem más, apenas são, constituindo uma espécie biológica. No debate bioético, tem havido uma passagem direta de fatos para valores, de modo que o fato do humano ser biologicamente vulnerável justificaria uma opção valorativa pela superação de algumas características biológicas. Postulando uma tensão entre fatos e valores, nosso objetivo é mostrar a pertinência de submeter os meios biotecnocientíficos de melhoramento humano à regulação proveniente da proteção da liberdade de escolha baseada na autocompreensão existencial do indivíduo (que chamaremos de escolha hermenêutica), medida fundamental para evitar ou combater formas de opressão num contexto biopolítico.

Palavras-chave: biologia humana, melhoramento humano, biotecnociência, biopolítica, escolha hermenêutica.

* Doutorando do Programa de Pós-Graduação em Filosofia da Universidade Federal do Rio de Janeiro (PPGF-UFRJ), Rio de Janeiro, Brasil. Professor Colaborador da UFRJ. $<$ contatoacademico@hotmail.com>.

* * Professora Associada do Departamento de Filosofia da Universidade Federal do Rio de Janeiro, Rio de Janeiro, Brasil. Docente do Programa de Pós-Graduação em Filosofia (PPGF-UFRJ). Endereço Postal: Lgo de São Francisco, 01 sl 310 - Centro - Rio de Janeiro, RJ, Brasil - CEP 20051-070. <mcdias1964@gmail.com>.

\begin{tabular}{|l|l|l|l|l|l|}
\hline Veritas & Porto Alegre & v. 58 & n. 1 & jan./abr. 2013 & p. 61-86 \\
\hline
\end{tabular}




\begin{abstract}
One way to understand the human is by their biology. It seems ambiguous. On the one hand, there are biological characteristics that give rise to complex and highly specialized skills, which open up possibilities of its own, distinct from the 'positive' from other living beings. On the other hand, there are characteristics that make human life finite and relatively vulnerable, which tend to be 'negative' interpretation. In both cases, there are biological characteristics that in themselves are neither good nor bad, only constituting a biological species. In the bioethical debate, there is a direct passage of facts to values, so the fact that the human being biologically vulnerable justify an evaluative choice by overcoming some biological characteristics. Postulating a tension between facts and values, our aim is to show the relevance of the subject biotechnoscientific means of human enhancement to the regulation from the protection of freedom of choice based on the existential self-understanding of the individual (we'll call hermeneutics choice), a key measure to prevent or combat forms of oppression in a biopolitical context.
\end{abstract}

Keywords: human biology, human enhancement, biotechnoscience, biopolitics, hermeneutics choice.

\title{
Introdução
}

De acordo com a Transhumanist Declaration (2009), a humanidade, há muito influenciada pela ciência e tecnologia, será ainda mais profundamente afetada por elas no futuro próximo. Os avanços biotecnocientíficos poderão incrementar potenciais humanos em níveis nunca alcançados, combatendo traços limitantes da sua natureza biológica. Isso significa que o transumanismo, grosso modo, aposta nos avanços da biotecnociência para ampliar capacidades, a saúde e o bem estar de seres humanos e não-humanos, por meio da alteração das suas biologias, o que geraria benefícios e melhorias vitais.

É razoável que um indivíduo, que aposta na razão técnico-científica; que esposa valores como o prazer, a saúde, o bem estar e a longevidade; que entende que doenças e deficiências, bem como todas as formas de sofrimento físico, mental e psicológico decorrentes delas devem ser evitadas, infira que há características da biologia humana que impõem limites indesejáveis ao seu florescimento, devendo ser alteradas. Notase, porém, que as suscetibilidades citadas fazem parte da natureza biológica humana. Ou seja, num sentido constatativo, é normal haver doenças e deficiências, as quais são distribuídas diferencialmente entre os exemplares da espécie, causando dores e sofrimentos de distintas ordens. Essas são características da biologia humana. A doença, entendida como "(...) uma força biológica na vastidão da natureza humana, mostrando humanos e micróbios presos em um esforço darwiniano para a sobrevivência (...)" (PORTER, 2008, p. 74), é parte da humanidade. 
No entanto, apesar de recorrente e trivialmente factual, para a concepção de bem largamente compartilhada, doenças e deficiências são indesejáveis, exemplos de causas de dor e sofrimento nos humanos, tidas, por vezes, como uma forma de punição. ${ }^{1}$ Deste modo, vivenciados como um mal, elas deveriam ser combatidas, visando ao melhoramento da vida humana. É plausível afirmar que algumas doenças, deficiências, anomalias, más formações ou maus funcionamentos biológicos encurtam gravemente certos horizontes de florescimento. Os atos que realizamos no exato momento em que escrevemos este texto, atividade que nos constitui como sujeitos, sendo indispensáveis à nossa concepção pessoal de florescimento, seriam impossíveis, caso tivéssemos sido acometidos por alguns tipos de males. Como as biociências têm dado demonstrações mais ou menos confiáveis de que podem compreender os mecanismos biológicos humanos, incluindo os ligados diretamente a esses males, abre-se diante de nós um horizonte de possibilidades relativamente novo, sobre o qual alguns teriam razões para investir. Os recentes avanços biotecnocientíficos permitem que se aguarde não só métodos terapêuticos, mas de incremento de capacidades vivenciadas até hoje de acordo com padrões considerados "normais". Saúde, memória, inteligência, longevidade etc. acima da normalidade (estatística) estarão, em tese, à disposição, fato que, muito claramente, é/ou pode tornar-se alvo das aspirações humanas.

Tais possibilidades envolvem alguns riscos. Um deles é transformar fatos (construídos cientificamente) em valores universais, extravasando, inadvertida ou propositadamente, o discurso do campo da descrição para o problemático campo da prescrição, de modo que indivíduos sejam obrigados, inclusive, sob argumentos de cunho moral, a investir na alteração das suas características biológicas, contrariando sua percepção existencial. Tal equívoco seria a consequência inevitável da adoção de uma norma melhoradora de cunho biotecnocientífico, com conteúdos predeterminados e universais, possuindo traços totalitários, que afronta a liberdade de cada um de, conforme sua autocompreensão, escolher que meios de alteração vital aduzir a si, ato ao que daremos o nome de escolha hermenêutica.

O horizonte hermenêutico individual, do qual deriva a liberdade de escolha hermenêutica, é considerado como condição do estatuto de sujeito de um indivíduo. Um sujeito, diferentemente de um objeto, é dotado da capacidade positiva de auto-atribuição, bem como da capacidade negativa

Recorrendo à etimologia, PORTER, Roy (2008) relaciona disease (dis-ease), malaise (mal-aise) e illness à sensação de desconforto, aflição e dor, ressaltando que pain (dor) deriva de poena, designação latina de punição. 
de dizer não a uma altru-atribuição. Delas, depende a construção de um horizonte hermenêutico mais ou menos particular, constituído por convergências e divergências com o contexto vivido, o que cria uma narratividade própria. A seleção das opções contextuais disponíveis reforça e/ou desconstrói a narratividade vital individual. Considerando os meios de melhoramento humano como meios disponíveis, refletimos, então, sobre o que a imposição de alterações biológicas, tácita ou explicitamente baseadas em juízos de valor, pode implicar em termos de reificação do humano, encurtamento ou enviesamento do horizonte plural de florescimentos, gerando formas de opressão.

Em síntese, assim como Bradshaw e Meulen (2010), a problemática examinada aqui se refere aos limites da obrigação de melhorar (obligation to enhance) frente à liberdade de escolha (chance to choice) em um contexto em que a vida e a política tornaram-se faces de uma mesma moeda. Considerando, consoante Esposito (2010), que isso ocorre em meio a uma política em nome da vida (biopolítica) que convive, justapõe-se e contrapõe-se a uma vida submetida ao comando da política (biopoder), formas de apagamento vital, sobretudo, no tocante à vida individual, são um risco constante. Temendo formas de opressão travestidas de bem, nossa tese é que o melhoramento humano deve respeitar a perspectiva de um indivíduo cuja liberdade de escolha hermenêutica está preservada, a fim de que, como expressão do paradigma da imunização (ESPOSITO, 2010), ele possa ser dispensado de obrigações gravosas que um coletivo (Estado ou comunidade) se lhe imporia indevidamente, sob o pretexto de melhoramento da sua vida. A presente análise investe numa normatização da política da/sobre a vida a partir do indivíduo, que é o nosso foco neste artigo, embora não compreendamos indivíduo como algo isolado de um contexto, pelo contrário, sua inserção em um meio ambiente social é condição de possibilidade da ideia de escolha hermenêutica. Mas, haja vista o nosso foco, e cientes da tensão entre demandas individuais e interesses coletivos, doenças e deficiências são tomadas, aqui, precisamente nos casos em que seus efeitos concernem prioritária ou exclusivamente ao indivíduo, de modo que excluímos casos em que há efeitos nocivos diretos e importantes à comunidade em que ele está inserido (por exemplo, psicopatias e sociopatias).

Partimos da premissa da tensão entre juízos de fato, referentes a proposições assertivas (verdadeiras ou falsas); e juízos de valor, referentes a proposições normativas (certas ou erradas). Embora não seja completamente inválida, a fronteira entre terapia e melhoramento é prenhe de pontos de imprecisão (BESS, 2010), o que nos leva a admitir, como segunda premissa do presente artigo, que mudanças na biologia 
com caráter terapêutico são iniciativas melhoradoras que dependem do endosso do indivíduo. Ademais, considerando que a não intervenção sobre 'anormalidades' (doenças e deficiências) é consideravelmente mais controversa do que sobre 'normalidades' (elevar o nível de características 'normais'), optamos por enfrentar a questão mais polêmica.

A última premissa desta reflexão é a que chamamos de realidade biopolítica, que fundamentamos na perspectiva sustentada por Esposito (2010), para o qual, atualmente, "já não é concebível outra política que não seja uma política da vida, o sentido objectivo e subjectivo do termo" (p. 32). Noutras palavras,

A política penetra directamente na vida (...). E então, se não existe uma vida natural que não seja, ao mesmo tempo, também técnica; se a relação a dois entre bios e zoé deve agora, ou talvez desde sempre, incluir como terceiro termo correlativo, a techne, como supor uma relação exclusiva entre política e vida? (ESPOSITO, 2010, p. 31).

Portanto, é sob o umbral enigmático da biopolítica, para imiscuir termos de Foucault e Esposito, em que a vida está sob intensivo, extensivo e detalhado controle e promoção política, que se situa o melhoramento humano, o que nos obriga a lidar com as características e os possíveis riscos de uma vida politizada.

A partir dessas premissas, a presente análise sustenta a liberdade de escolha individual baseada no que constitui o horizonte hermenêutico do indivíduo - fatores sociais (culturais, ideológicos, religiosos, éticos, políticos) e características biológicas particulares - como uma forma de regular alguns efeitos biopolíticos do melhoramento humano biotecnocientífico.

\section{Sobra biologia, política e biopolítica}

Em um sentido fundamental, o termo 'humano' é um termo de classificação biológica: um indivíduo é humano por ser um membro da espécie Homo Sapiens.

(INGmar PERsson e Julian SAVulescu; 2010)

Uma das maiores revoluções que o pensamento científico operou nas concepções de mundo decorreu das pesquisas de Charles Darwin. Desde que apresentou à humanidade os resultados da sua investigação, em meados do século XIX, defendendo a sua teoria da evolução das espécies, os humanos passaram a ser compreendidos como um ser biológico, estando, assim, submetidos às leis da natureza, notadamente a da evolução (RICHARDS, 2000). 
Malgrado as inúmeras críticas recebidas tanto acerca de pontos específicos quanto da teoria como um todo, as quais a colocam como que numa 'montanha-russa' de prestígio-desprestígio (DEGLER, 1991), acredita-se, até hoje, que a tese evolutiva, com ajustes ou não, senão verdadeira, é a mais plausível explicação formulada sobre a constituição dos seres vivos. Desse ponto de vista, o humano é o resultado de bilhões de anos de evolução, de modo que aquilo que o define, como qualquer outro ser vivo, é, fundamentalmente, suas características biológicas em constante metamorfose. Estas, em conjunto, servem inclusive para distinguir espécies. Humanos não são tartarugas, as quais, por sua vez, não são cachorros porque suas biologias diferenciam-nos em alguns aspectos genotípicos e fenotípicos bastante relevantes. Essa compreensão evolucionista é hiperbólica, isto é, tudo no humano é fruto de um processo evolutivo, o que inclui o cérebro e tudo a ele relacionado, enseja, por exemplo, a noção de darwinismo neural, como analisam Almeida e El-Hani (2006).

Eminentes cientistas, tais como o psicolinguísta canadense Steven Pinker e o neurofisiologista brasileiro Miguel Nicolelis, têm apostado na descrição empírico-científica na natureza humana entendida, portanto, como imanente, biológica, e não transcendental ou metafísica. Para Pinker (2002), a natureza humana é formada por faculdades cognitivas e emocionais que são universais nos espécimes saudáveis do Homo Sapiens. Para Nicolelis (2011), natureza humana é o conjunto da enorme variedade de comportamentos especializados produzido pelo cérebro humano como um órgão formado por "imensas redes neuronais altamente conectadas e de operação extremamente dinâmica, conhecidas pela alcunha de circuitos neurais" (p. 18). Nicolelis torna a sua posição ainda mais radical e precisa, afirmando que tudo em nós advém do funcionamento cerebral,

(...) cada ato de pensamento, criação, destruição, descoberta, ocultação, comunicação, conquista, sedução, rendição, amor, ódio, felicidade, tristeza, solidariedade, egoísmo, introspecção e exultação jamais perpetrado por todo e qualquer um de nós, nossos ancestrais e progênie, ao longo de toda a existência da humanidade (2011, p. 18-9).

O legado darwinista e a biologia são polêmicos, mas não podem ser desconsiderados, a não ser que se assuma uma postura dogmática. A 'entrada do humano no reino da natureza biológica' operada pela teoria darwinista, dentre outros efeitos, contribuiu, conjuntamente com o desenvolvimento das biociências, para mudanças importantes em outros campos, como é o caso do filosófico (ALMEIDA e EL-HANI, 2006). Abrantes et al. (2011) organizaram um conjunto de textos em que 
se aborda alguns dos pontos mais relevantes para a chamada filosofia da biologia. Nele, são apresentadas e discutidas as fortes influências do conhecimento biológico sobre nossas visões do mundo, destacando, por exemplo, conceitos como de função, leis naturais, organização e classificação biológica, adaptação, evolução e ética evolutiva, herança, entre outros. Chediak (2005) analisa como teorias evolutivas, inclusive não-darwinistas, interessam à filosofia, no tocante ao entendimento do processo de individuação relacionado à ideia de evolução por seleção natural. Churchland (2008), por sua vez, aborda como a neurociência tem impactado e poderá impactar ainda mais seriamente a filosofia, notadamente quanto à compreensão da moralidade, haja vista o recente, promissor e polêmico campo da neurociência da ética. Com efeito, o resultado da interface biologia-filosofia é visto, por exemplo, com a criação do que Almeida e El-Hani (2006) chamam de epistemologia evolutiva, um ramo do naturalismo epistemológico, que é "caracterizada pelo uso de um pensamento evolucionista na tentativa de entender a cognição e o conhecimento humanos" (p. 336). Buchanan (2011b) identifica a ignorância quanto à biologia evolutiva como um dos pontos frustrantes do debate sobre melhoramento humano. Em síntese, é implausível desprezar a importância do conhecimento biológico.

Dada a sua controvertida história e aos seus usos nefastos, a biologia é uma das ciências mais, por assim dizer, temidas. O trecho em epígrafe desta seção pode ser interpretado como a 'quinta essência' dos famigerados reducionismo e determinismo biológicos. A ideia de que ser humano é um ser vivo como qualquer outro, sem prerrogativas de foro moral de cunho especista (SAVULESCU, 2009), com características biológicas inatas sobre as quais não exerce controle tem sofrido ataques sistemáticos. Defendê-la impõe enfrentar pechas como a reducionista, a biologista, a determinista, a inatista, como se pode ver na crítica dirigida por Luc Ferry (FERRY e VINCENT, 2011).

Tais termos podem expressar mais propriamente preconceitos, mesmo que bem intencionados, do que críticas válidas. Sobre o termo reducionismo, registramos que ele é polissêmico e não serve para definir um campo como um todo. Para Martínez (2011), ele pode, por vezes, ser usado como uma espécie de rótulo impreciso. Tendo em vista a pertinente abordagem de Schopenhauer (2003), tal termo pode ser usado muito mais como um rótulo odioso (o $32^{\circ}$ estratagema retórico analisado pelo filósofo) do que como uma crítica bem fundamentada. A biologia, a filosofia, a sociologia, bem como a metafísica podem ser reducionistas quanto a alguns aspectos, mas não relativamente a outros.

A argumentação desenvolvida por Ferry está voltada contra dois tipos de determinismo, a fim de sustentar dada ideia de liberdade 
humana. Ele ataca, ainda que de modo menos prestigiado, o que chama de materialismo determinista de cunho historicista, referindo-se especificamente a Marx. Focalizando, mais diretamente, o determinismo de cunho biológico, haja vista o escopo do livro (analisar princípios filosóficos e biológicos), aduz o conceito de biologismo de Jean-Didier Vincent: "a ideologia materialista segundo a qual a determinação última, talvez única, de nossos comportamentos, e inclusive sociais e culturais (sic), seria de origem natural" (FERRY e VINCENT, 2011, p. 18).

Postulando a ideia de liberdade como a capacidade de descumprir códigos naturais e históricos, deixando o passado para trás e inventando a sua história, para Ferry, ambos os determinismos são perigosos e enganosos, representando o que ele chama de "falsas ciências (...), ideologias que, crendo às vezes sinceramente enraizar-se em fatos averiguados, soçobram realmente nas ilusões mais clássicas da metafísica e da teologia dogmáticas" (p. 19). Ferry arremata sua defesa de uma ideia de liberdade evocando a hipotética separação radical entre natureza (seres vivos em geral) e cultura (tipicamente humana).

Em que pese a correção dos questionamentos acerca de formas de determinismos unilaterais absolutos, Ferry equivoca-se em alguns pontos. Primeiramente, não fica claro em que sentido os materialismos citados seriam metafísicos. Se eles, como o autor afirma, baseiam-se na ideia de que tudo provém, respectivamente, da realidade sócio-histórica ou da biologia, como, por definição, poderiam ser metafísicos? O termo mais apropriado para o determinismo biológico seria a de naturalismo. Este, por sua vez, tem de ser precisado, senão, torna-se insustentável. Vejamos a tentativa ferryana de desnaturalizar o humano.

Ferry endossa a concepção rousseauniana de que ao passo em que "o animal faz um com a natureza. O ser humano faz dois" (FERRY e VINCENT, 2011, p. 25), pois este é capaz de questioná-la. De pronto, identificamos a tentativa de desnaturalizar, desbiologizar o humano através da artificial dissociação das noções de animal e humano. O humano, como um tipo biológico do reino animal, deve também ser entendido pela sua animalidade. Em segundo plano, cabe questionar a capacidade humana supracitada provém de onde que não da sua natureza? A ideia de que os Homo Sapiens tornam-se humanos, distanciando-se da natureza é objetável por uma razão bem simples: o humano é um ser biológico naturalmente capaz de modificar a natureza, inclusive a sua. A criação e recriação de códigos (sociais e/ou biológicos) é a realização da natureza humana, e não um afastamento dela. Com isso, a liberdade (enquanto autonomia), o que quer que ela signifique e em que graus ela seja concretizada pelos indivíduos, está na natureza biológica humana, podendo, até mesmo, ser identificada, descrita e manipulada 
cientificamente, como os transumanistas apostam (BOSTROM, 2005a) e os bioconservadores temem (HABERMAS, 2004).

As tentativas de sustentar a ideia de liberdade tornando-a caudatária da hipotética separação citada têm sido sistematicamente contestadas. Por exemplo, as teorias biológico-evolutivas são evidentes antagonistas, na medida em que apontam evidências que subsidiam a tese da inextrincável relação entre fatores intrínsecos ('naturais') e extrínsecos ('ambientais') na constituição na natureza dos seres vivos. É na natureza biológica humana, na sua genética que estão inscritas as condições de possibilidade da dita ação livre (VALENZUELA, 2005), as quais se realizam em um contexto sócio-histórico determinado, que atua como fator condicionante. Ou seja, a consagrada e duradoura teoria evolucionista, ao ressaltar a relação supracitada, delineou, ao mesmo tempo, a naturalização-biologização e a sua politização da vida humana, o que dá subsídios à afirmação de Esposito (2010) de que a vida é de onde provém e para qual retorna o poder, a política. Uma ordem política não é a saída do humano do reino da natureza, mas uma forma de organização deste. Esta, por sua vez, repercute sobre aquele, formando uma dobra que se desdobra, perenizando o processo.

Tal entendimento é encontrado na genealogia nietzschiana e foucaultiana. Segundo Esposito (2010), além de Nietzsche, Foucault bebeu do evolucionismo darwiniano, “(...) cuja duradoura actualidade não está em ter substituído à história 'a grande e velha metáfora biológica da vida' mas, pelo contrário, em ter reconhecido também na vida os sinais, os desvios e os acasos da história" (p. 51). Esposito ressalta, citando Foucault mais uma vez, que "é de Darwin que vem, aliás, a consciência de que a 'vida evolui, e a evolução das espécies viventes é determinada, até certo ponto, por acidentes que pode ser de natureza histórica'" (p. 51-52). Em suma, "história e natureza, vida e política, entrelaçaram-se, solicitamse, violentam-se segundo um ritmo que faz duma ao mesmo tempo matriz e resultado provisória da outra" (p. 53), de modo que "(...) uma natureza humana definível e identificável enquanto tal, independentemente dos significados que a cultura, e portanto a história, lhe imprimiram no curso do tempo, é coisa que não existe" (p. 52).

Considerando que não há vida natural (reino da natureza), de um lado, e vida política (reino da liberdade), do outro, nossa abordagem da questão do melhoramento humano irá reiterar a premissa biopolítica. Mas para que haja clareza acerca do que estaremos adotando, aqui, como premissa biopolítica, talvez seja necessário discorrer e descartar algumas interpretações da biopolítica contemporâneas.

De acordo com Esposito (2010), há quatro grandes momentos/ vertentes do pensamento biopolítico. O primeiro, desenvolvido nos 
1920, de origem alemã e sueca, emerge em meio a uma concepção vitalista de Estado, operando uma naturalização da política. Apoiado na metáfora do Estado-corpo, que é “(...) soldado pela relação harmónica entre os seus órgãos (...)" (ESPOSITO, 2010, p. 34), recorre-se ao discurso biológico, especialmente referindo-se ao par antinômico fisiologiapatologia e à imunidade para discernir os parasitas (anormais) do corpo político, que lhe causam prejuízos, dos cidadãos que o preservam, os cidadãos-protetores. Propugnando uma espécie medicalização social, cabia à política preservar o organismo (Estado, sociedade) dos agentes patogênicos (humanos tidos marginais, anormais, desajustados), o que deu lugar a práticas totalitárias, como as nazistas.

A metáfora utilizada é indevida por vários motivos. Destacamos a impropriedade de ocultar o fato biológico da diversidade, tratando os diversos indivíduos como órgãos (partes) de um único corpo (político). Isso vai de encontro com um aspecto da biologia evolutivo, qual seja, que o pluralismo, a variação, é um traço fundamental da evolução, segundo a teoria da evolução variacional de Darwin (MAYR, 2009). Assim, é falsa a ideia de um corpo biológico composto por partes harmônicas, o que torna indevida a analogia com o corpo político. Ademais, a imposição de um padrão biológico-político (melhorador ou eugênico) gera uma biocracia, cujos efeitos nefastos são largamente conhecidos.

A segunda formulação biopolítica emerge nos 1960, na França, sendo influenciada pela derrocada da biopolítica nazi. Esposito (2010) denomina-a de neo-humanística ou domesticada, ressaltando seu tom metapolítico, em detrimento do naturalístico, na medida em que visa a incorporar forças espirituais (por exemplo, forças da justiça, da caridade, da verdade) contrárias à fatalidade das forças cegas da natureza (violência e vontade de poder). O resultado é que, mais do que uma biopolítica, tem-se uma ontopolítica.

Como se pode depreender, esta perspectiva coaduna-se com a de Ferry no tocante precisamente à "(...) mitologia humanística que define o homem por oposição ao animal, a cultura por oposição à natureza (...)" (ESPOSITO, 2010, p. 39), embora um dos seus representantes - Edgar Morin - critique-a, o que cria o que Esposito denomina de incerteza semântica. Haja vista as críticas que já apresentamos, resta clara a nossa discordância acerca dessa vertente biopolítica. Em todo caso, cabe-nos apontar que um dos seus efeitos, quanto ao melhoramento humano, é selecionar arbitrariamente aquilo que deve ser promovido e o que deve ser combatido na nossa natureza, utilizando a biotecnociência para promover o que Sloterdijk (2000) chama de tendências domesticadoras (forças espirituais). A falta de uma elaboração conceitual precisa - que, talvez, sequer seja possível - gera uma série de riscos. Uma biopolítica 
domesticadora vaga, que arrefece as tendências embrutecedoras (forças cegas) (SLOTERDIJK, 2000), pode simplesmente obrigar os indivíduos a adotarem um humanismo de ajustamento de condutas através, por exemplo, de meios de controle cerebral.

A terceira ronda dos estudos biopolíticos, nos 1970, é anglo-saxônica. Após a declinação organicista e neo-humanística, vê-se nascer uma com um "(...) marcado pendor naturalístico" (ESPOSITO, 2010, p. 41). À esfera da natureza é dado o caráter de parâmetro privilegiado da determinação política. Em outras palavras, a política é explicada e normatizada pela natureza, contrariando a ideia de que os acontecimentos sociais têm de ser compreendidos por explicações históricas complexas. Citando Somit e Peterson", biopolítica é o "termo comumente usado para descrever a abordagem daqueles cientistas políticos que usam os conceitos biológicos e as técnicas de investigação biológica para estudar, explicar, prever e às vezes também prescrever o comportamento político" (ESPOSITO, 2010, p. 43).

Esposito identifica o problema desta perspectiva com clareza: “(...) uma coisa é estudar, explicar, predizer e outra prescrever" (idem). A naturalização do social - atinente à nascente sociobiologia - revela-se um exemplo da falácia naturalista. Indo do plano do ser ao do dever ser sem mediações justificadas, os condicionantes sociais da vida humana são desconsiderados, dando lugar ao famigerado determinismo biológico. Neste campo biopolítico, a tecnociência, com seu poder descritivo e manipulador, tornar-se-ia a última palavra política, pois só ela seria capaz de compreender e de solucionar os problemas sociais. Sob a égide da razão funcionalista e instrumentalizadora, como Habermas (1997) diagnosticou, a política é reduzida a questões de ordem técnica, de modo que "(...) a autocompreensão culturalmente determinada de um mundo social da vida é substituída pela autocoisificação dos homens, sob as categorias de acção racionalidade dirigida a fins e do comportamento adaptativo" (p. 74).

O quarto movimento biopolítico é reportado a Foucault. Retomando traços supracitados, a biopolítica foucaultiana caracteriza-se pela imbricação natureza-histórica, vida-política. A natureza não está lá e a história aqui; tampouco a vida existe em si, para além da política. Assim, não é possível investir sobre um sem envolver o outro. Dentre as positividades desta concepção biopolítica, sublinhamos a capacidade de elidir, de uma só vez, separatismos radicais, dualismos e pretensões de neutralidade. Quanto ao melhoramento humano, a biopolítica foucaultiana retira de nós todo e qualquer subterfúgio, obrigando-nos a

2 "Biopolitics in the Year 2000". In: (Eds.). Research in biopolitics, 1996. 
refletir sobre que tipo de vida e política, bem como de natureza e história queremos construir, bem como a responsabilizar-nos por ele. Não há como argumentar que agíamos em defesa do corpo político bem ajustado e imune, que visávamos ao humanismo ou que respeitávamos a nossa natureza. O melhoramento humano é, ao invés, uma tomada de posição, e a nossa posição é que a liberdade de escolha hermenêutica deve ser garantida, pois é este tipo de vida (biológica-política-natural-histórica) que julgamos ser a mais adequada, a moralmente aceitável, tendo em vista um ordenamento social e político que não oprima o indivíduo. Ou seja, a escolha hermenêutica é uma força biopolítica que queremos colocar em relevo ante a crescente biotecnocientificação da vida humana.

Em verdade, o desenvolvimento biotecnocientífico, que promete tornar o corpo e a vida transparentes, é uma força biopolítica extraordinária e profundamente controvertida. O estágio atual das biociências constrange, e promete constranger ainda mais, nossas convicções sobre o humano, incluindo a nossa crença na liberdade. O temor demonstrado por Ferry e outros acerca dos efeitos dos recentes desenvolvimentos, por exemplo, da neurociência para a crença na liberdade humana pode ser interpretado como apenas parcialmente justificável. Sem dúvida, as biociências carregam em si um grau de incerteza. As convicções mais firmes da atualidade podem ser refutadas futuramente. Destarte, é correta a postura crítica que mantém um nível plausível de dúvida acerca das 'verdades científicas'. Todavia, para nós, há críticos que ultrapassam este nível, assumindo um ceticismo hiperbólico insustentável, como parece ser o caso de Ferry, beirando a desconsideração dos fundamentos biológicos da humanidade.

Postulando que a incerteza científica induz-nos à prudência e criticidade epistemológica, mas não ao ceticismo absoluto, e reafirmando a implausibilidade do desprezo do conhecimento biológico, vejamos algumas novidades que o chamado avanço biotecnocientífico tem apontado, as quais podem gerar importantes mudanças quanto à compreensão do que é o humano, modificando substantivamente o modo como a filosofia reflete sobre, por exemplo, a moralidade, o que pode revolucionar a biopolítica.

Haggard (2011) menciona pesquisas que relatam a gravação de impulsos elétricos neuronais, em diversas áreas do lobo frontal medial, anteriores ao movimento voluntário. É como se a preparação para o movimento fosse anterior à vontade de realizá-lo, o que põe em dúvida os mecanismos da vontade humana e a relação entre ela e a consciência. Algo semelhante pode ocorrer com outras ações às quais devotamos o estatuto de tomadas de decisão, o que colocaria a crença de que temos livre-arbítrio, intenções conscientes e responsabilidade em questão. Roskies (2006), por 
sua vez, discorda da preocupação com o determinismo, sustentando que, a despeito de se o universo é determinista ou não, problemas acerca da autodeterminação humana permanecerão. O argumento é interessante, especialmente porque amplia o questionamento sobre a liberdade para o âmbito do ponto de vista indeterminista. Ora, se não há determinismo, e todos os eventos são aleatórios, há arbítrio humano? Se as ações humanas forem absolutamente aleatórias, o indeterminismo pode comprometer a tese da liberdade humana ainda mais radicalmente.

Ainda no campo das neurociências, algumas das mais importantes novidades referem-se a uma parte do cérebro que tem sido identificada como responsável por uma série de tarefas extremamente importantes (aprendizagem; tomadas de decisão; cognição social e moral; avaliação de riscos), a saber, o córtex pré-frontal ventromedial (LUO et al., 2006; MOLL e OLIVEIRA-SOUZA, 2007). Há evidências de que danos nesse lócus cerebral comprometem as respostas emocionais e tomadas de decisão, notadamente as ligadas à moralidade. A incipiência de áreas como a neurobiologia, neurofisiologia e neurociência da ética clama a uma atitude de espera e prudência. No entanto, uma série de estudos tem apontado para mecanismos neuronais ligados a anomalias, inclusive aquelas que implicam graves ameaças não só ao indivíduo, mas, sobretudo, à sociedade, como é o caso de algumas psicopatias, bem como os traços tradicionalmente vinculados à noção de self humano. Intenções, volições, ações planejadas, aprendizagem de regras sociais, tomadas de decisão, autocontrole, empatia, moralidade, enfim, a liberdade e a necessidade humanas ingressam numa nova e, provavelmente, promissora etapa (ANDERSEN e CUI, 2009; NORTHOFF, 2010; CHURCHLAND, 2011; PASTOR-BERNIER e CISEK, 2012).

Perspectiva-se que a compreensão de tais mecanismos permita, em médio prazo, que o self humano tenha seus traços selecionados conforme seja desejado, sendo alterado, planejado, programado ou, como alguns defendem, neuroaperfeiçoado (CHURCHLAND, 2011; SAVULESCU, MEULEN e KAHANE, 2011). Isso parte da noção de sujeito cerebral, isto é, "a figura antropológica que incorpora a idéia de que o ser humano é essencialmente reduzível a seu cérebro" (ORTEGA e VIDAL, 2007, p. 257), a qual torna iminente a possibilidade de uma reantropologização (NORTHOFF, 2010). Quer dizer, uma nova compreensão do que seja o humano pode estar em acelerada rota de surgimento, ressignificando, inclusive, o seu estatuto de ser livre e autodeterminável. Isso, obviamente, desperta os temores de indivíduos como Luc Ferry e Jürgen Habermas, Francis Fukuyama, Leon Kass, entre outros autores que podem ser enquadrados como bioconservadores; mas anima aqueles que apostam em um futuro pós-humano (BOSTROM, 2005a). 
Evidentemente, vozes dissonantes erguem-se contra o prometeísmo biotecnocientífico (ROSKIES, 2006; KABLE e GLIMCHER, 2009), bem Como apontam para a relatividade dos juízos de valor envolvidos (KOCK, 2010). Até mesmo entre os pró-melhoramento ou antimelhoramento têm críticas e ressalvas (PERSSON e SAVULESCU, 2008; BUCHANAN, 2011a), não sendo, como alguns acusam, ingênuos tecnoprofetas.

Sem subscrever dualismos costumeiramente suscitados, segundo os quais ou bem o melhoramento representa exclusivamente um perigo ou uma promessa, nossa questão é, antes, sobre como cada indivíduo ou grupo de indivíduos pode interpretar as possibilidades que a biotecnociência disponibiliza e, em tese, disponibilizará futuramente. Será que não há uma abertura hermenêutica das experiências da doença e da deficiência? Por que um biodesign do self é melhor do que deixá-lo ao acaso? É cominatório que um incremento do autocontrole seja, em si, um bem? Por que a promessa da vida infinita seria absolutamente desejável?

A complexidade humana, notadamente do equipamento cerebral ou dos processos que envolvem o mental, alguns já comprovadamente externos aos limites físicos do corpo humano, ${ }^{3}$ ainda parece bastante incompreensível. Não se sabe se a vida humana será compreendida na sua totalidade um dia. É dubitável que ela possa ser reduzida às explicações biocientíficas, sobretudo dada as características epistêmicas das biociências. No entanto, podemos decidir se devemos ou não prosseguir nos estudos sobre isso, que valor conferir a estes, além de refletir sobre como arcar com os efeitos gerados pelas suas explicações. Os riscos de uma biopolítica naturalística são conhecidos e foram apontados anteriormente. A falácia naturalista, um dos pontos fracos do debate bioético atual, desponta como uma base para o que queremos problematizar aqui. Sobre ela, o melhoramento humano pode tornar-se tirânico.

\section{Juízos de valor sobre a natureza humana e a ideia de melhoramento}

Entendo o comportamento moral como uma resposta construtiva às dependências e carências decorrentes da imperfeição da estrutura orgânica e da fragilidade permanente da existência corporal (evidente sobretudo em fases da infância, da doença e da velhice).

(JÜRGEN HABERMAS; 2004)

Para Rousseau (2005), há uma faculdade que distingue incontestavelmente o animal (não-humano) do Homem, a saber, a faculdade de

3 Debates sobre a mente estendida. 
se aperfeiçoar. Quer dizer, no século XVIII, antes, portanto, de Darwin, o filósofo suíço, um dos pais do humanismo moderno, defendia que todas as outras faculdades humanas estavam submetidas à tipicamente humana de investir em seu melhoramento, considerando as circunstâncias vividas. Assim, para ele, ao passo que um animal (não-humano) já é o que será para o resto da sua vida, depois de alguns meses, o humano é um ser diferenciado, pois é perfectível. O Homem, então, torna-se propriamente humano ao deixar para trás o que era originalmente.

É com a negação da sua origem que aquela faculdade humana permite que o humano avance, progrida, humaniza-se, aperfeiçoa-se. Essa ideia rousseauniana estava completamente harmonizada com a tradição eugênica, para a qual, em linhas gerais, o humano pode melhorar a si mesmo, desde que invista em desnaturar-se (ESPOSITO, 2010). Cabe salientar que, ao contrário dessa noção que rivaliza natureza e humanidade, a ideia de melhoramento humano é mais bem entendida se considerar-se que, concomitantemente, nega aspectos da natureza humana e afirma outros. Malgrado discordemos da posição assumida por Habermas (2004), ela serve-nos como um exemplo disso. Como se pode ver na epígrafe desta seção do artigo, Habermas partilha a noção de que o humano é caracterizado por imperfeições e fragilidades permanentes. Além disso, para ele, doenças e deficiências representam desvios, anormalidades ou carências funcionais resultantes dessa natureza imperfeita. Contudo, na interpretação habermasiana, tal admissão não implica aceitar a intuição que, se algo é imperfeito e frágil, ele deve, se possível, ser aperfeiçoado, fortalecido. Para Habermas (2004), a vulnerabilidade humana deve ser mantida intocada, na medida em que seria o eixo em torno do qual as coisas como a autonomia, a dignidade humana, a autenticidade, a autocompreensão ética enquanto espécie e a moralidade articulam-se. É óbvio, portanto, que Habermas abrace uma lista de valores compreendidos de dado modo e ligados, supostamente, ao fato da vulnerabilidade. É esse conjunto de valores que subsidia a sua perspectiva bioconservadora.

É curioso notar que ele admite como moralmente permitida o que chama de eugenia negativa, isto é, a terapia. Ou seja, aquilo que for tido como anormal pode ser alterado. Inobstante os problemas já apresentados na literatura acerca da distinção entre eugenia positiva e negativa (BOSTROM e ROACHE, 2008; DIAS e VILAÇA, 2010), o que merece ser ressaltado é a dupla interpretação habermasiana acerca do fato da biologia humana. Por um lado, há características que devem ser corrigidas; por outro, há outras que devem permanecer indisponíveis à instrumentalização. A fronteira entre o que pode e deve ser alterado e o 
que não deve é tênue, mas é constituída por aquilo que supostamente promoverá os valores (imprecisos, por sinal) endossados por Habermas, pressupondo que eles são caudatários de alguma fragilidade bioestrutural. Destarte, valorizando dada noção de normalidade biológica como possuindo uma relevância moral intrínseca, ${ }^{4} \mathrm{em}$ vez de human plus, como o pró-melhoramento, Habermas defenderia uma espécie de human minus.

A controvertida perspectiva habermasiana tem adversários. Uma das contrapropostas mais polêmicas provém do médico-filósofo australiano Julian Savulescu, que defende o chamado Principle of Procreative Beneficence (PB). Segundo este princípio, "casais ou 'reprodutores simples' devem selecionar a criança, dentre as possibilidades de crianças que poderiam ter, cuja expectativa de desenvolver uma vida melhor seja maior do que a das outras" (SAVULESCU, 2001, p. 415). A questão não tarda a surgir: o que é uma vida melhor? Que características biológicas configuram uma vida com maior propensão à felicidade, ao florescimento, à realização? O chamado fato do pluralismo evidencia que não há muito consenso, em sociedades tidas como liberais e democráticas, acerca do que tais termos representam concretamente. Assim, além das discordâncias razoáveis e irredutíveis sobre o que é ser feliz, florescer ou realizar-se, os traços biológicos que as garantiriam mediatamente são ainda mais imprecisos, especulativos ou arbitrários. Para Bennett (2009), "é impossível dar conta do que seja a 'melhor' criança e, assim, pode-se argumentar que este Princípio é praticamente inviável” (p. 266).

Savulescu (2007) responde a essa previsível objeção, neste caso, feita por Michael Parker. ${ }^{5}$ De acordo com Savulescu, cumpre fazer uma clara distinção entre o valor de uma vida inteira e o valor de uma característica individual para uma vida. Para ele, quando usamos um teste genético, estamos apenas tomando a decisão sobre que característica(s) é melhor ter, e não sobre se a vida da pessoa será ou não bem sucedida, já que isso envolve uma série de fatores imprevisíveis (SAVULESCU, 2007).

Ao adentrar a polêmica seara da escolha de que filho se quer ter, o PB savulescuano suscitou uma série de críticas. Uma delas veio de Sandel (2007), para o qual os filhos devem ser considerados presentes ou dádivas (gifts), quiçá, divinos, e não objetos da concepção arbitrária ou da ambição dos pais, o que os tornaria produtos ou objetos. Em resposta a ela, Savulescu e Kahane (2009) rejeitam essa que parece ser uma intuição

4 Para uma interessante crítica a esse entendimento, ver KAHANE, G; SAVULESCU, J. The concept of harm and the significance of normality. Journal of Applied Philosophy, 29 (2012), p.1-15.

5 PARKER, Michael. The best possible child. Journal of Medical Ethics, 33 (2007), p. 279-283. 
bastante comum, reiterando o PB. Para eles, a escolha de uma criança com maiores possibilidades de desenvolver uma boa vida não quer dizer, em absoluto, que ela será melhor do que outra existente ou que ela será perfeita. Além disso, rejeitando por completo a ideia de que filhos são presentes da natureza ou de Deus, eles afirmam que a escolha de uma pessoa em potencial - ou seja, não há determinismo - com maiores condições de desenvolver, nos termos circunstanciais da atualidade, uma vida melhor, não é um ato de reificação da pessoa, mas sim um ato que geralmente norteia a relação entre pais e filhos, a saber, um ato de beneficência. Este primordial ato de bondade poderia, inclusive, em contradição com a concepção habermasiana, fomentar a autonomia e a autenticidade, na medida mesmo em que ampliaria as possibilidades de realização da pessoa. É pertinente notar como os mesmos valores foram reinterpretados no tocante à sua relação com a biologia humana. Enquanto Habermas entende que eles seriam comprometidos, Savulescu e Kahane defendem que serão promovidos.

O princípio moral defendido por Savulescu, conforme sua definição já aponta, visa ao bem da descendência. Outro detalhe é que, para Savulescu, há uma obrigação moral formal dos pais, cujo conteúdo seria concernente às suas concepções de boa vida, ressalva que torna a proposta relativamente adequada ao nosso enfoque, pois não imporia valores universais. Contudo, na medida em que defende a utilização de testes genéticos para selecionar, justificadamente, futuros humanos sem doenças incuráveis e, até mesmo, escolher genes saudáveis para constituí-los, tem de assumir o valor-saúde - ou valor não-doença ou não-deficiência - como uma 'pedra angular' de uma vida melhor.

Não há nada propriamente novo nisso, pois, conforme a análise foucaultiana, a saúde tornou-se um imperativo a partir do século XVIII (FOUCAULT, 2007). Este imperativo, segundo Ortega (2008), atingiu o valor de moralidade, de um bem inquestionável ao lado do valor bemestar, de modo que a contemporaneidade é marcada por uma espécie de ditadura do healthism e do wellness. Em completa consonância com esse entendimento secular, para Savulescu, doenças e deficiências comprometem a qualidade de vida e o bem-estar humanos, reduzindo as chances de uma pessoa realizar uma possível concepção de boa vida. Mas, cabe salientar que isso não é só um juízo de fato, mas também de valor, valor este que pode ser justificado e legitimado, mas que precisa ser entendido como tal.

Uma deficiência física - por exemplo, a falta de um membro inferior comprometeria, absoluta e necessariamente, a boa vida de um guitarrista? Por seu turno, se houver um gene da 'boa memória', será que não esquecer nada seria, cominatoriamente, algo que promoveria a boa vida? O que se 
diria da necessidade de esquecer fatos traumáticos? Os limites práticos são previstos pelo PB. Todavia, a escolha justificada tem de partir de alguma pressuposição normativa, senão, ela seria meramente arbitrária.

Ressaltamos que não estamos defendendo que a falta de um membro seja desejável, tampouco que a perda da memória seja algo bom. Ao invés, de acordo com nossa concepção de boa vida e até mesmo de autonomia, não o são. Novamente, a questão que salientamos é que não é possível objetivar, homogeneizar e universalizar a 'positividade' ou 'negatividade' das características biológicas. Harris (2007) contesta essa perspectiva, sendo um exemplo do entendimento pró-obrigação. Partindo do plausível raciocínio de que "em termos de funcionamento humano, um melhoramento é, por definição, uma melhoria quanto ao estado anterior" (p. 9), ele infere que o melhoramento humano atende aos interesses tanto da sociedade quanto do governo, entendimento questionável, haja vistas as discordâncias que constituem as sociedades pluralistas. Em que pese tal ressalva, para ele, no uso da nossa liberdade, temos a obrigação de adotá-lo, o que envolve uma antinomia (liberdade-obrigação).

Decerto, uma perspectiva como essa, costumeiramente associada ao movimento transumanista, suscita críticas, por vezes, bem severas, como a de Kock (2010). Apontando o que, para ele, é um argumento admiravelmente conciso, que dá novos tons melódicos à antiga sintonia eugênica, cujo resultado é destrutivo, má-fé que é promovida como um ideal elevado, Kock sentencia o transumanismo como um credo antagônico à ideia de respeito pela pessoa humana em sua diversidade. Embora haja importantes pontos ressaltados em sua crítica, Kock incorre em, pelo menos, dois equívocos, a saber, abordar o transumanismo como algo unívoco, homogêneo, portanto, passível de uma crítica simétrica e abrangente, não dando a devida atenção às importantes diferenças entre vertentes e autores que o constituem; e desenvolver uma abordagem sumária de alguns autores - notadamente, Nick Bostrom - selecionando, estrategicamente, afirmações que corroboram a crítica que deseja fazer, sem apresentar a proposta deles na sua complexidade. Assim, por vezes, traça-se uma caricatura do pensamento transumanista, o que o torna facilmente - mas injustamente - criticável. Bostrom (2005b), por exemplo, é bastante incisivo sobre a necessidade de o incremento biotecnocientífico ser seguido por uma crítica e reexame permanentes, bem como por uma ampla gama de informações, a partir das quais as pessoas decidirão quais técnicas aplicar a si mesmas e à sua descendência. $O$ trecho abaixo não deixa dúvidas quanto a isso. Bostrom (2005b) afirma que

De saída, transumanistas, tipicamente, enfatizam a liberdade individual e a escolha individual na área das tecnologias de aperfeiçoamento. Os 
seres humanos diferem amplamente sobre suas concepções do que seja sua própria perfeição ou do que consistiria seu melhoramento. Alguns querem desenvolver em uma direção, outros noutras, e alguns preferem permanecer como são. Seria moralmente inaceitável alguém impor um padrão único ao qual todos teriam de se conformar. As pessoas devem ter o direito de escolher que tecnologias melhoradoras, se for o caso, querem usar (p. 11).

O artigo de Bradshaw e Meulen (2010) oferece uma crítica que nos parece mais pertinente. Analisando, mais diretamente, os argumentos de James Hughes ${ }^{6}$ e de Anders Sandberg, ${ }^{7}$ contrastam a perspectiva transumanista pela obrigação (Hughes) com a pela escolha livre acerca do melhoramento (liberdade morfológica) (Sandberg). Citando Hughes, os autores afirmam que ele entende como uma ideia muito fundamental aquela segundo a qual temos o dever e direito de dar às crianças os corpos mais saudáveis e capazes que pudermos. Sobre Sandberg, afirmam que ele sustenta que a liberdade morfológica deve ser garantida como um direito negativo, e não como um dever, assegurando, portanto, a escolha de não melhorar.

Segundo os autores, Hughes utiliza o exemplo das crianças surdas para defender que os pais que não intervêm com vistas à cura da surdez não devem ser auxiliados pelo governo ou por seguradoras de saúde, devendo, inclusive, poder ser processados pelos próprios filhos quanto estes alcançarem a maturidade. Bradshaw e Meulen recorrem, com isso, ao exemplo de Louisa, uma acadêmica e linguista surda, que, considerando a pressão médica e social pelo uso do implante coclear, ${ }^{8}$ afirma que "(...) não é porque ele 'está lá' (disponível) que é automaticamente bom ou corresponde à situação particular e ao ambiente da pessoa" (BRADSHAW e MEULEN, 2010, p. 671; termo entre parênteses incluído). Para os autores, ser mais saudável e mais capaz, termos de Hughes, pode ser estados situacionalmente dependentes, atravessados por uma série de fatores sociais e subjetivos, o que explicaria o porquê de Louisa e outros deficientes auditivos quererem viver em comunidades surdas.

6 HUGHES, James. Citizen cyborg: Why democratic societies must respond to the redesigned human of the future. Cambridge, MA: West View Press, Perseus Books Group, 2004.

7 SANDBERG, Anders. Morphological freedom - Why we not just want it, but need it. 2001. <http://www.nada.kth.se/ asa/Texts/MorphologicalFreedom.htm>, acessado em: 7.01.2013.

8 Dispositivo eletrônico de alta tecnologia, com um componente interno (cirurgicamente inserido no ouvido interno) e um externo (composto por microfone, microprocessador de fala e transmissor), que transmite o sinal elétrico para o nervo auditivo em indivíduos com severa perda auditiva. 
Bradshaw e Meulen (2010), em suma, partem da perspectiva de liberdade de Isaiah Berlin, ${ }^{9}$ a fim de enfrentar o risco político e social da opressão praticada por um Estado de tipo intervencionista, bem como outro risco ressaltado por Berlin, a saber, do abandono. Ao mesmo tempo em que uma liberdade como abandono (não-intervencionismo) dos menos capazes ou afortunados traz problemas, a excessiva 'proteção' gera uma liberdade como opressão. Ao passo que certos indivíduos sofreriam caso o Estado os abandonasse, não oferecendo ou impondo certos tratamentos, a alegação de que o Estado sabe do que os indivíduos necessitam para serem 'livres' poderia ensejar restrições ou obrigações, a despeito de sua vontade ou escolha. Com isso, formas nefastas de controle podem ser implementadas como uma biopolitização da existência humana supostamente beneficente.

Para Bradshaw e Meulen (2010), num contexto de sociedades cooperativas, os benefícios da diversidade morfológica devem ser coletivamente garantidos pelas novas tecnologias e pelas instituições políticas, a fim de que subgrupos e membros individuais de uma sociedade possam, se quiserem, explorar outras morfologias ou estilos de vida. A liberdade morfológica, segundo eles, é capaz de minimizar os riscos tanto do abandono quanto da tirania, perspectiva concordante com a ideia de escolha hermenêutica.

Em suma, para alguns, a surdez pode representar um mal, pois compromete o funcionamento da audição, ao qual é atribuído grande valor. Nesta visão, a surdez prejudicaria o indivíduo, de forma que a opção seria pelo combate das características biológicas que a promove, visando ao bem e ao melhoramento. Contudo, ainda que isso soe inaceitável para alguns, há indivíduos cujo horizonte hermenêutico hierarquiza tal funcionamento abaixo de outros valores, tal como a fé religiosa. Para quem esposa a crença de que Deus é o autor da vida e que tudo que faz é bom ou tem um propósito benéfico, manipular a biologia, ao invés de melhorar, poderia encerrar a existência do indivíduo no pior dos mundos possíveis. Por isso, a liberdade enquanto autocompreensão e escolha hermenêutiva deve, para nós, assumir a posição de valor fundamental, a partir do qual funcionamentos biológicos são avaliados, de modo que o status normativo destes não é substantivo, mas sim de valor derivado. A alteração biológica para promover um funcionamento deve ser avaliada pelo crivo da promoção daquele valor fundamental. Assim, o indivíduo, visando a promovê-lo, avalia que alterações na sua biologia são mais ou menos apropriadas.

9 BERLIN, Isaiah. Two concepts of liberty; and Introduction to five essays on liberty. In: HARDY, H. (ed.). Isaiah Berlin Liberty. Oxford, UK: Oxford University Press, 2002. 


\section{Considerações finais}

Consagrado pela literatura filosófica como uma falácia naturalista, deduzir o dever ser de um é, um valor de um fato, seria um erro. Quanto à biologia humana, do fato de termos características biológicas que constituem uma estrutura orgânica prenhe de suscetibilidades não se pode inferir, logicamente, que sejam valoradas negativamente. Não há, analogamente, propriedades biológicas absolutamente más, tampouco boas, pois a biologia humana e as noções de bem e mal não compartilham propriedades. Assim, não se pode emitir tais juízos como se fossem relativos a fatos, mas sim a valores. Para que isso seja argumentativamente possível, ter-se-ia de demonstrar as razões pelas quais tais suscetibilidades são, elas mesmas, negativas. O que nos parece correto dizer é que julgamos socialmente como negativas ou positivas características físicas ou biológicas concretas de indivíduos, sem que, para tal, tenhamos que pressupor uma relação de identidade entre os predicados descritivos atribuídos aos fatos e aos juízos valorativos que incidem sobre os mesmos.

Ainda que soem absurdas, as questões que temos de responder são: por que é negativo ter uma deficiência? Por que estar doente é ruim? O que, propriamente, elas limitam? Por que ultrapassar tais limites pode ser considerado algo positivo, mas também um mal? Por que devemos ou não alterar a nossa biologia, evitando efeitos indesejados? Ser ilimitado é necessariamente um bem? Não adoecer, ter deficiências ou, no limite, morrer é algo absolutamente bom? A essas complexas questões, associamos a concepção de que as características biológicas do humano estabelecem outro tipo de limite, a saber, para as nossas práticas intervencionistas. Tomemos um exemplo: diante de um indivíduo com alguma deficiência física, mas sem qualquer comprometimento mental ou cognitivo, indivíduo que não compreende a sua deficiência como um mal, como algo que impede o seu florescimento, o melhoramento humano, no nosso entendimento, teria de respeitar os limites impostos pela autocompreensão individual - que decorre de características da biologia humana - não intervindo sobre o limite físico mencionado. Quer dizer, a intervenção sobre uma característica biológica funcionalmente limitante (um limite físico-funcional) é, por sua vez, limitada por outra característica biológica do humano.

Não buscamos defender, aqui, uma positividade objetiva e absoluta das características biológico-estruturais humanas, pois isso iria de encontro à ideia de escolha hermenêutica. Ao contrário, fatos são descritíveis, não sendo, prima facie, nem bons, nem maus. Apenas as suas consequências, num segundo momento, podem ser valoradas. Além 
disso, apenas se a relação causa-efeito puder ser determinada, o que é bastante questionável, é que as características biológicas associadas aos efeitos poderiam ser igualmente valoradas. Ainda que algumas suscetibilidades sejam tidas como ruins em dadas culturas, por terem sido assim interpretadas, quiçá de forma hegemônica, isso não significa que sejam em si ou universalmente ruins. Como temos argumentado, há sempre abertura para interpretações em outro sentido, um sentido que as torne positivamente valoráveis ou boas.

O debate em torno do conceito de natureza humana é um claro exemplo disso. A constatação (objetiva) de quais características constituem a natureza humana rivaliza claramente com a eleição (normativa) de quais devem ser selecionadas. Via de regra, faz-se uma opção pelo critério normalidade (PINKER, 2002), conceito bastante controverso. É bastante conhecida a polêmica historicidade dos conceitos de doença e saúde (KIPLE, 2008; SCLIAR, 2007), bem como o pluralismo de formas de percebê-las. Cada nova versão, cuja finalidade é superar as controvérsias das definições existentes, cria novos problemas, de modo que o dissenso parece incontornável (CAPRARA, 2003). A definição, por assim dizer, oficial, da Organização Mundial da Saúde, faz menção ao completo bem estar físico, mental, espiritual e social (SCLIAR, 2007), o que, obviamente, cria problemas tais como a necessidade de definir outro conceito (bem estar), bem como saber se alguém seria saudável, já que plenitude é algo irremediavelmente vago e, logo, indeterminável.

Ainda sobre uma abertura hermenêutica acerca dos estados biológicos, recorremos à abordagem de Porter (2008) sobre a diferença entre doença e enfermidade. Segundo ele,

(...) doença, geralmente, é uma coisa objetiva, freqüentemente desencadeada por um patógeno, tal como um bacilo ou um vírus, e marcada por uma constelação de sintomas - uma erupção cutânea ou elevação da temperatura. Enfermidade, por outro lado, denota algo subjetivo, sentimentos de mal-estar ou dor (PORTER, 2008, p. 75).

Ressaltando que o uso dos termos acima não é um mero rodeio semântico, pois “(...) palavras geralmente revelam sintomas de realidade subjacentes" (PORTER, 2008, p. 75), ele conclui que “(...) atualmente, o conceito científico de doença parece mais flexível, mais subjetivo e antecede conotações históricas (...)", oferecendo “(...) uma avaliação profunda sobre diferentes percepções culturais e mudanças com o passar do tempo" (idem, ibidem). Portanto, não há uma percepção unívoca acerca de doenças, mas ela varia tanto diacrônica quanto sincronicamente, ressaltando, mais uma vez, o valor da escolha hermenêutica. 
Inobstante essas observações, há coisas factíveis tidas como doenças e deficiências. Os cânceres existem; a falta de um membro é visível. Os exames por imagens tornam, em certa medida, o corpo transparente, de modo que há imagens de doenças como o Mal de Alzheimer (OLSON, 2005). No entanto, o modo como cada pessoa lida com elas varia (CAPRARA, 2003). Resgatando o exemplo supracitado, a perda de uma das mãos para um guitarrista pode não significar a mesma coisa que para um jogador de futebol. Semelhante perda nem mesmo tem de significar a mesma coisa, no mesmo grau, para dois guitarristas distintos.

No tocante às deficiências, Glover (2006) define o conceito como uma limitação funcional, não sendo simplesmente uma desvantagem socialmente construída. Para ele, as deficiências não diriam respeito a qualquer forma de limitação funcional, mas àquelas que comprometeriam capacidades indispensáveis ao florescimento humano, o que, por sua vez, estaria relacionado a uma noção de normalidade biológica. Então, a deficiência comprometeria a normalidade, envolvendo uma limitação funcional que, por si mesma ou na combinação com alguma desvantagem social, prejudicaria a capacidade de qualquer ser humano exercer o estado pujante atinente à espécie. Porém, há consenso em torno de quais capacidades são indispensáveis? A lista é igual para todos os humanos? Florescimento humano é um conceito preciso, unívoco, invariável? Pensamos que, ante ao exposto, respostas negativas a essas questões são as mais adequadas, o que reitera a necessidade de respeito ao pluralismo hermenêutico que sustentamos ao longo deste artigo.

Em suma, por mais que doenças e deficiências pareçam explicitamente maléficas, um horizonte de possibilidade de outras significações e percepções de aspectos da biologia humana, fundamentadas numa hermenêutica individual, podem existir legitimamente, considerando a positividade de uma ordem política marcada por pluralismos. Os indivíduos não devem estar sob um imperativo melhorador como algo unívoco, objetivo, obrigatório e universal, mas devem poder escolher, dentre os meios disponíveis, de acordo os parâmetros que envolvem fatores subjetivos, revelando que garantir a liberdade de escolha hermenêutica é um modo adequado de regular o melhoramento humano biotecnocientífico.

\section{Referências}

ABRANTES, P. C. et al. Filosofia da biologia. Porto Alegre: Artmed, 2011.

ALMEIDA, A. M. R.; EL-HANI, C. N. "Darwinismo neural: uma extensão metafórica da teoria da seleção natural". Episteme, 11 (2006), p. 335-356. 
ANDERSEN, R. A.; CUI, H. "Intention, action planning, and decision making in parietal-frontal circuits", Neuron, 63 (2009), p. 568-583.

BENNETT, R. "The fallacy of the Principle of Procreative Beneficence". Bioethics, 23 (2009), p. 265-273.

BESS, M. Enhanced humans versus "normal people": Elusive definitions. Journal of Medicine and Philosophy, 35 (2010), p. 641-655.

BOSTROM, N. "In defense of posthuman dignity", Bioethics, 19 (2005a), p. 202-214. $\overline{\text { p. 87-101. }}$

"Transhumanist values". Review of Contemporary Philosophy, 4 (2005b),

BOSTROM, N.; ROACHE, R. "Ethical issues in human enhancement". In: RYBERG, J.; PETERSEN, J.; WOLF, C (Eds.). New waves in applied ethics. London, UK: Pelgrave Macmillan, 2008, p. 120-152.

BRADSHAW, H. G.; MEULEN, R. T. "A transhumanist fault line around disability: morphological freedom and the obligation to enhance". Journal of Medicine and Philosophy, 35 (2010), p. 670-684.

BUCHANAN, A. Better than human. The promise and perils of enhancing ourselves. Oxford: Oxford University Press, 2011a.

. Beyond humanity? The ethics of biomedical enhancement. Oxford: Oxford University Press, 2011b.

CAPRARA, A. "Uma abordagem hermenêutica da relação saúde-doença". Cadernos de Saúde Pública, 19 (2003), p. 923-931.

CHEDIAK, K. "O problema da individuação na biologia à luz da determinação da unidade de seleção natural". Scientiae Studia, 3 (2005), p. 65-78.

CHURCHLAND, P. S. “The impact of neuroscience on philosophy". Neuron, 60 (2008), p. 409-411.

. Braintrust: What neuroscience tells us about morality. New Jersey: Princeton University Press, 2011.

DEGLER, C. N. In search of human nature: The decline and revival of darwinism in american social thought. New York: Oxford University Press, 1991.

ESPOSITO, R. Biopolítica e filosofia. Lisboa: Edições 70, 2010.

FERRY, L.; VINCENT, J-D. O que é o ser humano? Sobre princípios fundamentais da filosofia e da biologia. Petrópolis, RJ: Vozes, 2011.

FOUCAULT, M. Microfísica do poder. Rio de Janeiro: Graal, 2007.

GLOVER, J. Choosing children: Genes, disability, and design. Oxford: Clarendon Press, 2006.

HABERMAS, J. O futuro da natureza humana: a caminho de uma eugenia liberal?. São Paulo: Martins Fontes, 2004.

. "Técnica e ciência como 'ideologia'”. In:

"Ideologia". Lisboa: Edições 70, 1997, p. 45-92.

(Org.). Técnica e ciência como

HAGGARD, P. “Decision time for free will”. Neuron, 69 (2011), p. 404-406.

HARRIS, J. Enhancing evolution: The ethical case for making better people. New Jersey: Princeton University Press, 2007. 
KABLE, J. W.; GLIMCHER, P. W. "The Neurobiology of decision: Consensus and controversy". Neuron, 63 (2009), p. 733-745.

KIPLE, K. F. "História da doença". In: PORTER, R (Org.). História da medicina. Rio de Janeiro: Revinter, 2008, p. 11-46.

KOCK, T. "Enhancing who? Enhancing what? Ethics, bioethics, and transhumanism". Journal of Medicine and Philosophy, 35 (2010), p. 685-699.

LUO, Q. et al. "The neural basis of implicit moral attitude - An IAT study using eventrelated fMRI". NeuroImage, 30 (2006), p. 1449-1457.

MARTÍNEZ, S. F. "Reducionismos em biologia: uma tomografia da relação biologiasociedade". In: ABRANTES, P. C. (Org.). Filosofia da biologia. Porto Alegre: Artmed, 2011, p. 37-52.

MAYR, E. O que é evolução. Rio de Janeiro: Rocco, 2009.

MOLL, J.; OLIVEIRA-SOUZA, R. "Moral judgments, emotions and the utilitarian brain". TRENDS in Cognitive Sciences, 11 (2007), p. 319-321.

NICOLELIS, M. Muito além do nosso eu: a nova neurociência que une cérebros e maquinas - e como ela pode mudar nossas vidas. São Paulo: Companhia das Letras, 2011.

NORTHOFF, G. "Humans, brains, and their environment: Marriage between neuroscience and anthropology?". Neuron, 65 (2010), p. 748-751.

OLSON, S. "An image of disease". Science, 307 (2005), p. 1550.

ORTEGA, F. O corpo incerto: corporeidade, tecnologias médicas e cultura contemporânea. Rio de Janeiro: Garamond, 2008.

ORTEGA, F.; VIDAL, F. "Mapeamento do sujeito cerebral na cultura contemporânea". RECIIS, 1 (2007), p. 257-261.

PASTOR-BERNIER, A.; CISEK, P. "Making choices between rules or between actions", Neuron, 70 (2012), p. 382-384.

PERSSON, I.; SAVULESCU, J. "The perils of cognitive enhancement and the urgent imperative to enhance the moral character of humanity", Journal of Applied Philosophy, 25 (2008), p. 162-177.

p. 656-669.

"Moral transhumanism", Journal of Medicine and Philosophy, 35 (2010),

PINKER, S. The blank slate: The modern denial of human nature. New York: Viking Penguin, 2002.

PORTER, R. "O que é doença?". In: História da medicina. Rio de Janeiro: Revinter, 2008, p. 73-104.

RICHARDS, J. R. Human nature after Darwin. A philosophical introduction. New York: Routledge, 2000.

ROSKIES, A. "Neuroscientific challenges to free will and responsibility", TRENDS in Cognitive Sciences, 10 (2006), p. 419-423.

ROUSSEAU, J-J. Discurso sobre a origem e os fundamentos da desigualdade entre os homens. São Paulo: Martins Fontes, 2005.

SANDEL, M. The case against perfection: Ethics in the age of genetic engineering. Cambridge, MA: Harvard University Press, 2007. 
SAVULESCU, J. "Procreative Beneficence: Why we should select the best children", Bioethics, 15 (2001), p. 413-426. p. 284-288.

. "In defence of procreative beneficence", Journal of Medical Ethics, 33 (2007), . "The human prejudice and the moral status of enhanced beings: What do we owe the gods?". In: SAVULESCU, J.; BOSTROM, N. (Eds.). Human enhancement. Oxford: Oxford University Press, 2009, p. 211-250.

SAVULESCU, J.; KAHANE, G. "The moral obligation to create children with the best chance of the best life", Bioethics, 23 (2009), p. 274-290.

SAVULESCU, J.; MEULEN, R. T.; KAHANE, G. (Eds.). Enhancing human capacities. Oxford: Wiley-Blackwell, 2011.

SCHOPENHAUER, A. Como vencer um debate sem precisar ter razão. São Paulo: TOPBOOKS, 2003.

SCLIAR, M. "História do conceito de saúde". Physis, 17 (2007), p. 29-41.

SLOTERDIJK, P. Regras para o parque humano: uma resposta à carta de Heidegger sobre o humanismo. São Paulo: Estação Liberdade, 2000.

TRANSHUMANIST DECLARATION, 2009. http://humanityplus.org/philosophy/ transhumanist-declaration/, acessado em: 10.01.2013.

VALENZUELA, J. G. Genoma humano y dignidad humana. Barcelona: Anthropos Editorial, 2005.

Recebido em 18 de janeiro de 2013.

Aprovado para publicação em 25 de fevereiro de 2013. 